\title{
Leveraging Artificial Intelligence for Sustainability in the Textile and Fashion Industry
}

\author{
Su Yun Bae ${ }^{1 *}$ and Deborah G Wooldridge ${ }^{2}$ \\ ${ }^{1}$ Assistant Professor, Family and Consumer Sciences, Bowling Green State University, USA \\ ${ }^{2}$ Professor and Director, Family and Consumer Sciences, Bowling Green State University, USA
}

*Corresponding author: Su Yun Bae, Family and Consumer Sciences, Bowling Green State University, USA

Received Date: May 06, 2021

Published Date: May 20, 2021

\begin{abstract}
Environmental problems have posed serious threats to society. Given the enormous environmental footprints created by the fashion industry, fashion companies have developed strategic plans to achieve sustainability goals. While using biodegradable or recycled materials helps the environment, this article contends that the major environmental problems are caused by inaccurate demand forecasting and excess production. It discusses the role of artificial intelligence (AI) in improving demand prediction and supply chain performance using Bestseller India and IBM's AI products as examples.
\end{abstract}

Keywords: Artificial intelligence; Bestseller India; Fabric.ai; IBM Garage ${ }^{\mathrm{TM}}$; Sustainability

\section{Introduction}

Sustainability is a major research topic in textiles and fashion. This has prompted considerable interest in academia and industry as part of an effort to reduce environmental impact. The use of biodegradable materials [1], efficient energy use [2], slow fashion [3], the purchase of used clothing [4], and consumption reduction [5] are all examples of sustainable efforts. The most sustainable approach to apparel production is to plan ahead of time in the supply chain by creating designs that are environmentally conscious [6]. With this in mind, the majority of fashion brands have formally proposed sustainable plans that include lowering carbon footprints and using sustainable materials such as organic cotton or recycled materials.

The critical problem associated with the environmental impact of apparel production, on the other hand, is its poor forecasting process, which results in a large amount of unsold items. Despite the fact that manufacturers use the most environmentally friendly materials when creating fashion items, any production has an impact on the environment. If the amount of production is not accurately calculated, even sustainable production can harm the environment due to excess production along with the associated energy consumption and pollution. As a result, this article proposes that accurate demand forecasting and minimizing production are the most sustainable methods in association with apparel manufacturing. It addresses the importance of applying artificial intelligence (AI) in the textile and apparel industries as the best way to achieve sustainability, as well as an industry example of such implementation.

\section{Discussion}

AI is a term that refers to a machine's ability to behave intelligently [7]. Its machine learning algorithms have provided solutions for a wide range of complex business issues, including big data analysis [8], customer relationship management [9], and business optimization [10]. With the rise of environmental concerns, AI and its machine learning models have been 
investigated to aid in the promotion of sustainable business models (SBMs) and sustainable development goals (SDGs) [11]. According to the World Economic Forum, the apparel industry accounts for ten percent of global carbon emissions and is the world's secondlargest water user. What is worse, each year, 85 percent of all textiles are discarded, and washing certain types of clothing results in the release of thousands of pieces of plastic into the ocean [12]. These facts highlight the importance of implementing methods for accurately predicting fashion demand and production.

Fashion companies frequently fail to accurately forecast consumer demand. Although a company predicts that a purple color will be popular in the coming season, if customers do not like the color, the products go unsold and end up as waste. Consumers are fickle, and their needs are diverse, making fashion forecasting difficult. Furthermore, companies continue to make mistakes and fail to recognize product flaws. This is due to the difficulty in determining which features of a product customers dislike and why they return it. Even luxury brands that operate their businesses in order to create a sense of scarcity and limited access fail to produce the necessary number of products and end up burning unsold items to maintain their prestigious status, causing massive environmental problems [13]. As a result, using proper methods to identify product flaws and accurately forecast consumer demand is highly advantageous for both mass market and luxury brands in their pursuit of sustainability goals.

Bestseller and IBM are industry leaders in incorporating $\mathrm{AI}$ into supply chain systems for accurate demand forecasting and operational efficiencies [14]. Ranjan Sharma, Bestseller's Chief Information Officer and Head of Supply Chain Management, spoke with IBM at the National Retail Federation's 2021 Retail Big Show about the role of $\mathrm{AI}$ in the fashion industry. Bestseller India, a subsidiary of Bestseller headquartered in Denmark, adopted the IBM GarageTM to develop an AI-powered Fabric.ai to improve sales forecasting, increase sell-through rates, and reduce waste from unsold garments [15]. IBM GarageTM is a tried-and-true development framework for transforming businesses and cultures through the integration of people, processes, and technology. Fabric.ai uses machine learning to forecast consumer demand, sell more products at higher margins, and minimize unsold inventory. IBM Watson ${ }^{\circledR}$, which is also based on AI, recommends the best products to incorporate into new products and determines the optimal product mix for each retail store, improving overall supply chain efficiency and performance. For example, even if two products appear to be identical, certain items sell significantly better. Is it due to the neckline, collar, or color? AI technology aids in determining why one performs better than others. This information is used to create new designs. Instead of dealing with files and data, AI technology enables designers, merchandisers, and buyers to focus on tasks that add more value [16]. It is now much smoother for them to develop a product that is more in tune with consumer demand. Production plans that incorporate business intelligence greatly eliminate waste and have a lower environmental impact.

\section{Conclusion}

Environmental issues have posed significant threats to society. The fashion industry, as one of the most polluting industries, must adopt cutting-edge technologies to improve supply chain performance and reduce environmental footprints. Fashion items inspired by sustainable materials and design ideas benefit the environment. Environmental issues, on the other hand, will not be optimally minimized unless accurate demand forecasting and business intelligence are used to identify product flaws and improve supply chain efficiency. The fashion industry is oversaturated, so it is time to produce less and sell more. Excessive manufacturing is detrimental to the environment, and fashion companies must be aware of this. Many AI-based technologies have been developed to help with business problems and sustainability goals. These technologies, regardless of company size, can provide practical solutions to challenges that impede improving sustainable production and management. AI shed light on business problems in the pursuit of sustainability.

\section{Acknowledgement}

None.

\section{Conflict of Interest}

Authors declare no conflict of interest.

\section{References}

1. Laitala K, Klepp I, Henry B (2018) Does use matter? Comparison of environmental impacts of clothing based on fiber type. Sustainability 10(7): 2524

2. Resta B, Dotti S, Pinto R, Bandinelli R, Rinaldi R, Ciarapica FE (2014) Practices for environmental sustainability in the textile, clothing and leather sectors: The Italian case. International Journal of Operations and Quantitative Management 20(3): 193-225.

3. Jung S, Jin B (2016) From quantity to quality: Understanding slow fashion consumers for sustainability and consumer education. International Journal of Consumer Studies 40(4): 410-421.

4. Yan RN, Bae SY, Xu H (2015) Second-hand clothing shopping among college students: The role of psychographic characteristics. Young Consumers 16(1): 85-98.

5. Shaw D, Newholm T (2002) Voluntary simplicity and the ethics of consumption. Psychology and Marketing 19(2): 167-185.

6. Karpova EE, Kunz GI, Garner MB (2021) Going global: The textile and apparel industry. New York, NY: Fairchild, USA.

7. Nilsson NJ (1983) Artificial intelligence prepares for 2001. AI Magazine 4(4): 7.

8. Chen H, Chiang RHL, Storey VC (2012) Business intelligence and analytics: From big data to big impact. MIS Quarterly 36(4): 1165.

9. Ngai EWT, Xiu L, Chau DCK (2009) Application of data mining techniques in customer relationship management: A literature review and classification. Expert Systems with Applications 36(2): 2592-2602.

10. Vercellis C (2009) Business intelligence: Data mining and optimization for decision making. Chichester, UK: John Wiley \& Sons.

11. Di Vaio A, Palladino R, Hassan R, Escobar O (2020) Artificial intelligence and business models in the sustainable development goals perspective: A systematic literature review. Journal of Business Research 121: 283314

12. McFall-Johnsen M (2020) These facts show how unsustainable the fashion industry is. 
13. Bae SY (2019) Luxury, sustainability and the future: The case study of Burberry. The Research Journal of the Costume Culture 27: 64-71.

14. Clemente J (2020) Bestseller and IBM Garage bring sustainable fashion forward with Fashion.ai.
15. NRF (2021) Innovation at scale in the retail sector with Bestseller produced by IBM.

16. Tucker M (n.d.) In India, fashioning the future with AI 